\title{
Exploring Authentic Leadership in Relation to Pedagogical Development in Public and Private Sector Universities
}

\author{
*Said Saeed: PhD Scholar, Abdul Wali Khan University Mardan, KP \\ **Prof. Dr. Riasat Ali: Professor in Education, Department of Education AWKUM, KP
}

\begin{abstract}
The study aims at to explore the authentic leadership attributes (ALA) and its impact on pedagogical development. The objectives of the study were to investigate ALA of leaders and measure relationship between ALA and pedagogical development at university level. The population of the study was 6975. The sample of the study was 967. The mixed method approach was used to collect information from sample by using modified form of $A L Q$ developed by Walumbwa, Avolio, Gardener, Wernsing, \& Peterson (2008) and interviews. Analysis was done with percentage, Mean, STD, independent sample t-test, Pearson's rank correlation and thematic analysis. It was found that $r$ value (.426) which was significant at .000 showed significant positive and average level correlations between ALA and pedagogical development at university level. It is suggested that followers may be involved in positive activities and be provided more leadership opportunities for the achievement of organizational goal and personal development.
\end{abstract}

Keywords: Authentic Leadership Attributes; Pedagogical Development; Organization

\section{Introduction}

The global village is speedily changing and improving. The people are getting awareness about everything through education. All organizations are focusing on their objectives. Educational institutions are also trying to improve the instructional skills of teachers. But for that they need authentic leaders. The organizations of present time require authentic leaders (Avolio et al., 2004) to build up authentic leadership (AL) in their followers for positive and productive decision-making behaviors i.e. citizenship behavior, job satisfaction and pedagogical development. AL is a way of learning about self, and self-information; understanding and thoughtfulness to other positioning and a methodological cleverness that

*PhD Scholar, Abdul Wali Khan University Mardan, KP. Email: syedsaeed54@gmail.com

**Professor in Education, Department of Education, AWKUM. Email: riasat@awkum.edu.pk 
proceeds to the interaction of management actions (Warszewska-Makuch et al., 2015). Authentic leader is believed by others as the epitome of integrity and morality; and a harbinger of ethical purpose (Albert \& Vadla, 2009).

Organizational development means to maintain the survival of organization, strengthen the knowledge, skills and competence of followers and manage human resources regarding organizational behavior which is enhancing organizational effectiveness, improving pedagogical skills and organizational commitment for the achievement of organizational goals; managing conflict and communication in groups and improving individual habits, abilities and education for the organizational development.

Authentic leaders having relational transparency, idealized influence, ethical perspective, knowledge generation, self-awareness, balanced processing information, openness and fairness, integrity, objectivity, trust, honesty, leader-follower interaction, follower-centric in place of leader-centric attitude, collaborative and collective learning, truthfulness, kind attitude, generosity, and true self will have to bring development in organization for the achievement of organizational outcomes through human resources and to help them lead and also that they can model its use for others. Authentic leadership will cause organizations to collect, manipulate, observe, and report innovative and diverse kinds of organizational achievement and growth data; leaders will have to be adroit and proficient in doing this (Gardner et al, 2005).

\section{Statement of the Problem}

The main objective of this article is to investigate the attributes of authentic leadership and its relationship with pedagogical development of teachers at university level. The previous research works have shown that authenticity and authentic leadership have positive influences on the performance of the human resources, particularly on the professional development of teachers. Integrity, honesty, veracity, truthfulness, candidness, fear of God, leader-follower interactions, effective communication skills, knowledge and love for humanity are the authentic leadership attributes which play crucial importance in teachers' pedagogical development and in making future leaders.

\section{Objectives of the Study}

The objectives of the study were;

1) To investigate authentic leadership attributes of educational leaders at university level

2) To investigate pedagogical skills development at university level 
3) To measure relationship between authentic leadership attributes and pedagogical skills development in public and private sector universities

\section{Research Questions}

1. What are authentic leadership attributes of educational leaders at university level?

2. What is the existing status of pedagogical skills development at university level?

3. Is there a relationship between authentic leadership attributes and pedagogical skills development in public and private sector universities?

\section{Literature Review}

Authentic leadership (AL) is still at its nascent phase of evolution and displays some weaknesses in connection to validity and reliability of AL constructs and researchers are required to bring into consideration the positive and non-positive aspects of AL (Avolio, Walumbwa \& Weber, 2009). Context or identity not taking into consideration is a weakness of $\mathrm{AL}$, therefore, it is sought to explore through the lived experiences of participants that scrutinizing the setting based on environments affects numerous individualities (Jones, Kim, \& Skendall, 2012). In addition, the ethical aspect and criteria of information, has not been completely illuminated (Northouse, 2013).

AL theory says that leaders must display the crucial constituents-relational transparency (RT), self-awareness (SA), ethical perspective (EP), authentic behaviour (AB) positive psychological capital (PPC) and balance processing of information (BPI) of ALs to lead efficiently and successfully (Walumbwa et al., 2008). Avolio and Gardner (2005) reported that ALs is the epitome of self-awareness and principles; honesty and transparency in judgments.

AL are broadminded personalities, having emancipation from self-justifying partialities in contrast to immature individuals. AL are translucent, crystal-clear and not immature persons. They display intimate interactions which mirror their genuine attributes, uniformity, philosophies, standards and activities. Moreover, Ryan and Deci (2003) discussed that those who are the symbols of morality, self-truth in opposition to briberies, exterior intimidations, prizes and societal hopes, rank or position are authentic leaders. Authentic leaders are defined by the stability, uniformity and reliability of their actions in light of ethical perspective (Hsiung, 2012).

Balanced processing, internalized moral perspective, relational transparency, and selfawareness are the conceptual basis, have been branded by research studies for AL behavior 
(Gardner et al., 2005; Ilies et al., 2005; Walumbwa et al., 2008). Balanced processing is the objective analysis of all related information prior to final decision-making. Internalized moral perspective is characterized by the intrinsic ethical values and criteria of the attitude of leaders rather than by extrinsic influence of society, same age people as well as by organizational atmosphere (Gardner et al., 2005). Relational transparency is the name of individual openness such that the sharing of information willingly with others and communicating selfless opinions and frame of mind with groups members (Walumbwa et al., 2010). As a final point, self-awareness is getting information that how the followers think about his leadership as well as to know the drives and purposes and weigh his strong and weak points for the heightening of their authenticity and genuineness and efficiency using both self-learning and replicated self-perception (Walumbwa, Peterson, Avolio, \& Hartnell, 2010). These paradigms have been advocated scientifically and considered as the foundation for the validation and measurement of AL (Walumbwa et al., 2008; Walumbwa et al., 2010).

The progressively challenging teaching atmosphere of the current time has driven both intellectuals and researchers equally to admit the requirements for a more unpretentious practice of management (Avolio \& Gardner, 2005). The ways of manifestation of AL are countless, though, the concept is founded on self-truth and practice professed by followers as actual and unaffected (Shamir \& Eilam, 2005).

Leadership which has positivity, candidness, genuineness, transparency, decency and morality is called ALs. These days, it is admitted as a constructive style to institutional and administrative leadership that can handle the present day challenges (Walumbwa, Avolio, Gardner, Wernsing, \& Peterson, 2008). Self-awareness, ingenuousness, frankness, honesty, unpretentiousness, innocence and intelligibility in behavior and attitude are the qualities of AL. Information, evidences and knowledge are shared by authentic leaders that looked-for to make decisions, accept others' ideas, and reveal their particular ethical standards, purposes, and views and thoughts and passions. Followers are empowered by such attributes for the true assessment of the proficiency and ethical position of their leaders' deeds (Walumbwa, Wang, Wang, Schaubroeck, \& Avolio, 2010).

Followers' efficiency can be stirred and driven by AL (Walumbwa, Luthans, Avey, \& Oke, 2011). Followers are advanced and strengthened by their authentic leaders by revitalizing and energizing them with noble actions psychologically, ethically and morally that are contributing to their performance. The perspective of complementary congruity produces the question that whether the followers' performance is uniformly or differently affected or taking influence in different context and further elucidate that to what extent it is 
same and to what extent it is differ as influenced by AL (Grant, Gino, \& Hofmann, 2011). The complementary congruity theory further suggests the performance of the followers get influence from the authentic leader efficiently and this performance further improves due to the positive effect of authentic leaders. Particularly, the qualities and attributes of authentic leaders back and balance the required abilities and skills, for good performance of the followers (Luthans, Youssef, \& Avolio, 2007). ALs! Thy name is a relational process (Dasborough \& Ashkanasy, 2005). It is shown by the previous studies that the continuous connections and exchange of views of the leaders and followers with one another enhance the performance for the better achievement of organizational goals (Huang \& Luthans, 2013).

Avolio, Gardner, Walumbwa, Luthans, \& May, (2004) sought to examine that the performance of the followers has been positively influenced by AL. Gardner et al. (2005) and Kernis (2003), studied that for the achievement of frankness and candidness; candor and straightforwardness in their associations with their followers, authentic leaders adopts their inner values and true principles in their attitude. Avolio and Gardner (2005) argued that crystal clear decision-making and role model presentation is the universe of authentic leaders, and provide guidance to the followers and keep them connected with heart and sinews and keep them active and spry intellectually while performing their activities. Moral attitude of authentic leaders makes the availability of showing straight ways to the companions due to their desirability and believability as starring role representatives (Wang, Sue Yang, Luthans, Wang, \& Wu, 2014).

\section{Methodology}

The study was mixed method research in nature. Concurrent triangulation design (Convergent Parallel design) was used.

\section{Population of the Study}

The population was all VCs/ Deans, HEC approved supervisors, heads of departments (HODs), and teaching faculty of public and private sector universities of Khyber Pakhtunkhwa leading and teaching at different levels. HEC website was visited for the identification of the available population in twenty nine (29) public and private sector universities of Khyber Pakhtunkhwa. Twnenty nine (29) vice chancellors / (58) Deans, four hundred and theirty two (432) HODs, seven hundred and seventy two (772) HEC approved supervisors; and five thousand, seven hundred and forty two (5742) assistant professors and lecturers comprised the population of the study. 


\section{Sample of the Study}

Simple random and purposive sampling techniques were adopted for selection of leaders and teachers from 13 universities. The human resource sample comprised twelve (12 with 40\%) vice chancellors/ Deans, one hundred and ninety five (195 with 45\%) HODs, three hundred and fifty (350 with 45\%) HEC supervisors and four hundred and ten (410 with 8\%) assistant professors and lecturers; total sample of the study was nine hundred and sixty seven (967) from nine (9) public and four (04) private sector universities (45\%) of Khyber Pakhtunkhwa (Gay \& Mills, 2011).

\section{Data Collection Tools}

Questionnaires and in-depth interview were used as research instruments to collect data from the concerned participants and informants.

\section{Data Analysis and Interpretation}

Mean was applied to analyse the collected data.

The Mean Score $=1.00$--- $1.50=$ Strongly Disagree; the Mean Score $=1.51---2.50=$ Disagree

The Mean Score= 2.51--- 3.50= Undecided; the Mean Score= 3.51--- 4.50= Agree

The Mean Score $=4.51--5.00=$ Strongly Agree

\section{R.Q.1:- What are authentic leadership attributes of educational leaders at university level?}

Table 1

Self-Awareness among university leaders

\begin{tabular}{lllc}
\hline S. No & Statements & M & Std \\
\hline 1 & I can list my three greatest weak points. & 4.54 & .669 \\
2 & I can list my three greatest strong points. & 4.67 & .649 \\
3 & $\begin{array}{l}\text { I seek feedback as a way of understanding who I really am as } \\
\text { a person. }\end{array}$ & 4.43 & .666 \\
4 & I accept the feelings I have about myself. & 4.69 & .465 \\
5 & I consider myself answerable to all. & 4.54 & .810 \\
6 & I am aware of my own loopholes and openly discuss with & 4.53 & .667 \\
& followers. & 4.57 & 0.65 \\
\hline
\end{tabular}

Table 1 shows that respondents are "strongly agreed" with the five statements of selfawareness construct having mean scores 4.54, 4.67, 4.69, 4.54 and 4.53 which come in the (Range from 4.51 to 5.00) among leaders. Statements "I seek feedback as a way of understanding who I really am as a person" has the mean scores " 4.43 " which comes in the 
range $(3.51-4.50)$ indicates that respondents are agreed. The overall mean score 4.57 comes in the range (4.51 - 5.00) shows that all the respondents are strongly agreed with the construct of self-awareness of authentic leadership. The mean scores further show that the most of the leaders at university level are self-aware and have the attribute of self-awareness, which is the prime component of authentic leadership.

However, all the STD scores reflect that all the respondents have convergence in their opinions about the statements of self-awareness construct.

\section{Table 2}

Relational Transparency among university leaders

\begin{tabular}{lllc}
\hline S. No & Statements & M & Std \\
\hline 1 & I openly share my feelings with others. & 4.81 & .419 \\
2 & I let others know who I truly am as a person. & 4.73 & .440 \\
3 & I rarely present a "false" front to others. & 3.54 & .720 \\
4 & I confess to others for my mistakes. & 4.53 & .681 \\
5 & I almost always consult with my team before decision-making. & 4.83 & .388 \\
6 & I keep positive relations with followers. & 4.26 & .440 \\
& Overall & 4.45 & .514 \\
\hline
\end{tabular}

Table 2 indicates that respondents are "strongly agreed" (Range from 4.53 to 4.83) with the four statements. Statements "I rarely present a "false" front to others." and "I keep positive relations with followers." have the mean scores "3.54" and "4.26" which demonstrate that the respondents are agreed with two statements. The overall mean score 4.45 follows the range $(3.51-4.50)$ shows that all the respondents are agreed with all the statements. The mean scores further show that the leaders at university level have transparency in their relationship with followers and have the attribute of relational transparency, which is the key component of authentic leadership. However, most of the STD scores reflect that all the respondents are unanimous on their opinions about the statements.

Table 3

Balance Processing of Information among university leaders and followers

\begin{tabular}{llll}
\hline S. No & Statements & M & Std \\
\hline 1 & I seek others' opinions before making up my own mind. & 4.56 & .685 \\
2 & I listen closely to the ideas of those who disagree with me. & 4.74 & .539 \\
3 & I do not emphasize my own point of view at the expense of others. & 4.55 & .677 \\
4 & I listen carefully to the ideas of others before making decisions. & 3.51 & .751 \\
5 & My followers feel I am genuinely interested in serving them. & 3.71 & .847 \\
6 & I share my information with followers. & 4.15 & .575 \\
& Overall & 4.20 & .679 \\
\hline
\end{tabular}


Table 3 point to that respondents are "strongly agreed" (Range from 4.55 to 4.74 ) as come in range of strongly agreed (4.51 to 5.00) with the three statements and "agreed" (Ranged from 3.51 to 4.15 ) as come in the range (3.50 to 4.50). The overall mean score 4.20 move toward the range $(3.51-4.50)$ shows that all the respondents were agreed with all the statements. The mean scores further show that the leaders at university level have the balance processing of information within the outskirts of the university and have the quality of balance processing of information, which is an important component of authentic leadership. However, the standard deviation scores reflect that all the respondents are undivided in their opinions about the statements of balance processing.

\section{Table 4}

Ethical perspective among university leaders

\begin{tabular}{llll}
\hline S. No & Statements & $\mathrm{M}$ & $\mathrm{Std}$ \\
\hline 1 & My actions reflect my core values. & 4.66 & .668 \\
2 & I do not allow group pressure to control me. & 4.67 & .660 \\
3 & Other people know where I stand on controversial issues. & 4.70 & .638 \\
4 & My moral standards guide me what I see to do as a leader. & 4.70 & .638 \\
5 & I deal ethically with my followers. & 4.59 & .662 \\
6 & I look forward to creating genuine relationship through my & 4.59 & .662 \\
& association at work. & 4.65 & 0.65 \\
\hline
\end{tabular}

Table 4 describes that respondents are "strongly agreed" (Range from 4.59 to 4.70 ) with the all six statements. The overall mean score 4.65 follows the range $(4.51-5.00)$ displays that all the respondents are strongly agreed with all the statements. The mean scores further show that the leaders at university level are ethically strong and have the attribute of ethical perspective, which is a major component of authentic leadership.

However, most of the standard deviation scores reflect that all the respondents are exclusive in their opinions about the statements ethical perspective.

\section{Table 5}

Positive psychological capital among university leaders

\begin{tabular}{llll}
\hline S. No & Statements & M & Std \\
\hline 1 & I am optimistic in my performance as role model for my followers. & 4.59 & .662 \\
2 & I share common vision with my associates. & 4.49 & .809 \\
3 & I encourage my co-workers when facing difficulties. & 4.49 & .809 \\
4 & I try to become a model of authentic leadership attributes. & 4.48 & .809 \\
5 & The actions I take are always linked with my values. & 4.49 & .809 \\
6 & I am resilient and won't be unhappy for long. & 4.68 & .646 \\
& Overall & 4.53 & 0.75 \\
\hline
\end{tabular}


Table 5 refers to that respondents are "agreed" (Range from 4.48 to 4.49) with the four statements. Statements "I am optimistic in my performance as role model for my followers." and "I am resilient and won't be unhappy for long" having the mean scores "4.59" and "4.68" which express that the respondents are strongly agreed with these two statements. The overall mean score 4.53 emanates in the range (4.51 - 5.00) shows that all the respondents are strongly agreed with all the statements. The mean scores further show that the leaders at university level are hopeful, self-efficacious, resilient and optimistic; and have the attribute of positive psychological capital, which is a most important component of authentic leadership.

However, the standard deviation scores reflect that all the respondents have the similar opinions about the statements of positive psychological capita

\section{Table 6}

Pedagogical development among university teachers

\begin{tabular}{llll}
\hline S. No & Statements & M & Std \\
\hline 1 & I get motivation from my AL to accomplish my set goals & 4.13 & 0.72 \\
& AL enhances my instructional skill & 4.16 & 0.73 \\
3 & At work, I keep it up, even when things do not go well in classroom & 4.37 & 0.66 \\
4 & My leader inspires me for good teaching & 4.55 & 0.67 \\
5 & I am immersed (get involved deeply) in my teaching as directed by & 3.94 & 0.87 \\
& leader & 4.24 & 0.62 \\
\hline & AL encourages my persistence even in face of hurdles in classroom & 4.23 & 0.71 \\
\hline
\end{tabular}

Table 6 mentions that respondents are "agreed" (Range from 3.94 to 4.37) with five the statements as come in the range (3.51 to 4.50). Statements "My job inspires me" having the mean scores "4.55" which takes place in the range (4.50- 5.00) expresses that the respondents were strongly agreed. The overall mean score 4.23 emanates in the range (3.51 4.50) illustrates that all the respondents were agreed with all the statements of pedagogical development. The mean scores further show that the leaders at university level have the abilities to engage followers in the best of their activities for the development of the organization and well-being of the human resources and believe that pedagogical development is the best construct for the organizational development and a necessary element for the professional development of the teachers and other followers.

However, the standard deviation scores reflect that all the respondents have the alike opinions about the statements of pedagogical development. 


\section{Table 7}

Pearson Product Moment Correlations between self-awareness and pedagogical development

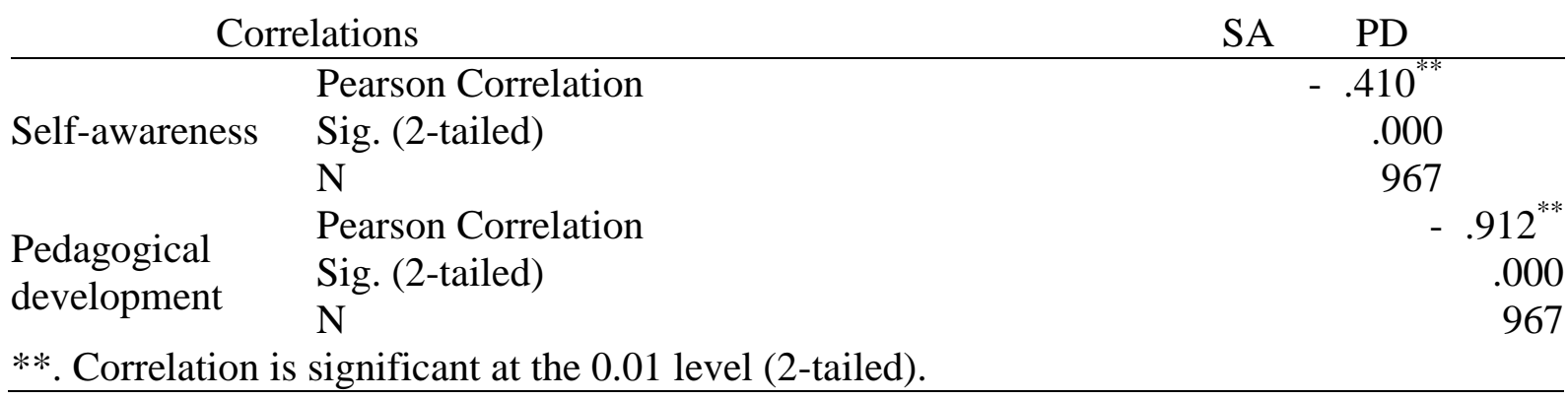

The above table illustrates that the self-awareness which is the first construct of authentic leadership has the highest correlation for pedagogical development ( $\mathrm{r}$ value .410) which is significant at .000

\section{Table 8}

Pearson Product Moment Correlations between relational transparency and pedagogical development

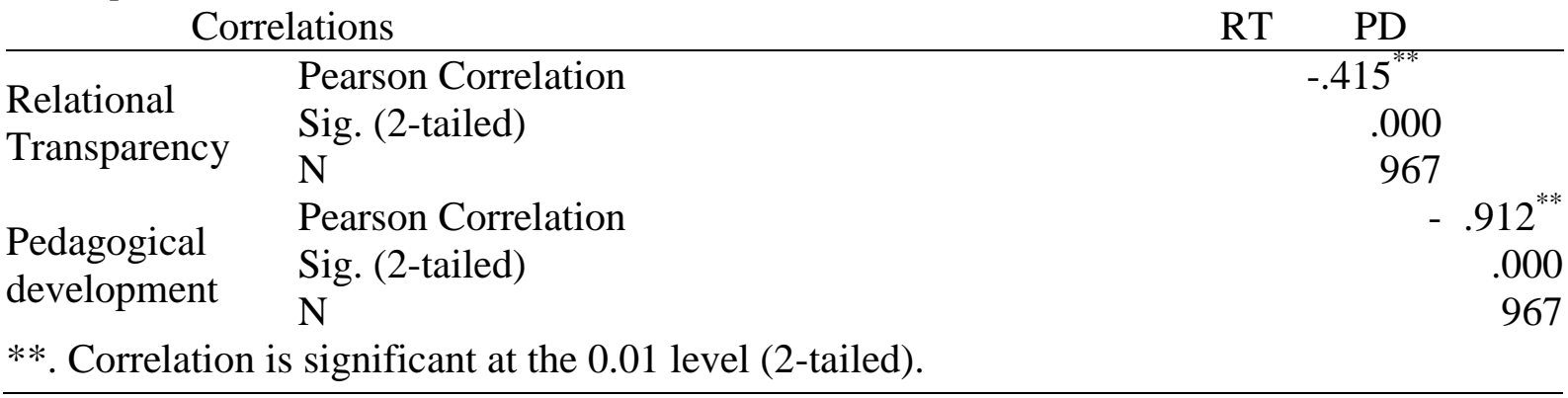

The above table illustrates that the relational transparency which is the most important construct of authentic leadership has the highest correlation for Pedagogical development ( $\mathrm{r}$ value .415$)$ which is significant at .000

\section{Table 9}

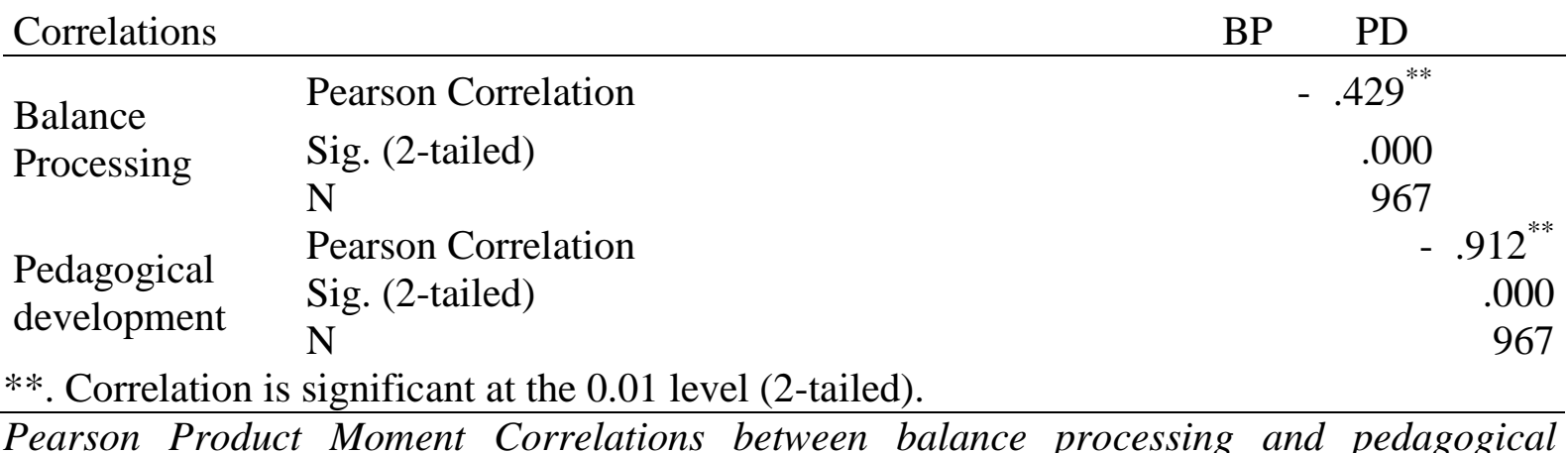
development 
The above table illustrates that the balance processing which is the third construct of authentic leadership has the highest correlation for Pedagogical development(r value .429) which is significant at .000

\section{Table10}

Pearson Product Moment Correlations between ethical perspective and pedagogical development

\begin{tabular}{|c|c|c|c|c|}
\hline \multicolumn{2}{|c|}{ Correlations } & EP & PD & \\
\hline \multirow{3}{*}{$\begin{array}{l}\text { Ethical } \\
\text { Perspective }\end{array}$} & Pearson Correlation & & $-.427^{* *}$ & \\
\hline & Sig. (2-tailed) & & .000 & \\
\hline & $\mathrm{N}$ & & 967 & \\
\hline \multirow{3}{*}{$\begin{array}{l}\text { Pedagogical } \\
\text { development }\end{array}$} & Pearson Correlation & & & $.912^{* *}$ \\
\hline & Sig. (2-tailed) & & & .000 \\
\hline & $\mathrm{N}$ & & & 967 \\
\hline
\end{tabular}

The above table illustrates that the ethical perspective which is the fourth construct of authentic leadership has the highest correlation for Pedagogical development(r value .427) which is significant at .000

Table 11 Pearson Product Moment Correlations between positive psychological capital and pedagogical development

Correlations

PPC PD

\begin{tabular}{llr}
\hline Positive & Pearson Correlation & $-.425^{* *}$ \\
Psychological & Sig. (2-tailed) & .000 \\
Capital & $\mathrm{N}$ & 967 \\
& Pearson Correlation & $-.912^{* *}$ \\
Pedagogical & Sig. (2-tailed) & .000 \\
development & $\mathrm{N}$ & 967 \\
$* *$ Correlation is significant at the 0.01 level (2-tailed). & \\
\hline
\end{tabular}

The above table illustrates that the ethical perspective which is the construct of authentic leadership has the highest correlation for Pedagogical development(r value .425) which is significant at .00 


\section{Table 12}

Pearson Product Moment Correlations between authentic leadership attributes and pedagogical development

\begin{tabular}{llr}
\hline Correlations & \multicolumn{1}{c}{$\begin{array}{c}\text { Authentic } \\
\text { leadership attributes }\end{array}$} & $\begin{array}{c}\text { Pedagogical } \\
\text { Development }\end{array}$ \\
\hline Authentic leadership & Pearson Correlation & $-436^{* *}$ \\
Attributes & Sig. (2-tailed) & .000 \\
& $\mathrm{~N}$ & 967 \\
Pedagogical & Pearson Correlation & - \\
development & Sig. (2-tailed) & 967 \\
$* *$ Correlation is significant at the 0.01 level (2-tailed). & \\
\hline
\end{tabular}

Medium positive correlation between the two variables, $r=.426, n=967, P<.000$, not as much of .05 indicating the statistical significance of the results. Cohen (1988) suggests the following guidelines: small correlation $(r=.10$ to .29$)$ medium correlation $(r=.30$ to .49$)$ large correlation ( $\mathrm{r}=.50$ to 1.0 ) (pp.79-81). In the light of this suggestion, there is medium correlation $(\mathrm{r}=.436)$ between authentic leadership attributes and Pedagogical development.

Table 13 Sector-wise correlation between authentic leadership attributes and pedagogical development in public and private sectors

\begin{tabular}{lllllll}
\hline \multicolumn{7}{c}{ Correlations } \\
\hline & $\begin{array}{l}\text { Type of } \\
\text { organization } \\
\text { (binned) }\end{array}$ & $\mathrm{N}$ & Mean & $\begin{array}{l}\text { Std } \\
\text { deviation }\end{array}$ & r value & $\begin{array}{l}\text { Sig. } \\
\text { level }\end{array}$ \\
$\begin{array}{l}\text { Authentic leadership } \\
\text { attributes }\end{array}$ & Public & & & & & \\
$\begin{array}{l}\text { Pedagogical development } \\
\text { Authentic leadership }\end{array}$ & Private & 483 & 140.817 & 7.52612 & .365 & .000 \\
$\begin{array}{l}\text { attributes } \\
\text { Pedagogical development }\end{array}$ & & 484 & 134.042 & 14.96052 & .529 & .000 \\
\hline
\end{tabular}

**. Correlation is significant at the 0.01 level (2-tailed).

The above table illustrates the mean, STD deviation, Pearson correlations and significance of the authentic leadership attributes and organizational development (teacher professional development) from sector-wise perspective. The mean score of the authentic leadership attributes and teacher professional development in public and private sector universities was 140.8170 and 134.0424 with standard deviation 7.52612 and 14.96052. The $r$ value between authentic leadership attributes and teacher professional development in public sector universities is $(\mathrm{r}=.365)$ which shows medium relationship which is highly significant as shown by the significant level (.000). The $\mathrm{r}$ value between authentic leadership attributes 
and teacher professional development in private sector universities is $(r=.529)$ which is indicative of large correlations as suggested by Cohen (1988) that small correlation ranges from (.10 to .29) medium correlation (.30 to .49) and large correlation (.50 to 1.0) which is highly significant as shown by the significant level (.000). These values show that relationship between authentic leadership attributes and teacher Pedagogical development in private sector universities is higher than public sector universities.

\section{Findings}

Major findings of the study were;

1. The overall mean scores $(4.57,4.45,4.20,4.65$ and 4.53$)$ showed that majority of university leaders were strongly agreed that self-awareness, relational transparency, balance processing of information, ethical perspective and positive psychological capital are the constructs of authentic leadership. (tables1, 2, 3, 4 \&5)

2. The overall mean score (4.23) illustrates that all the respondents were agreed with all the statements of pedagogical development. The mean scores further show that the leaders at university level have the abilities to engage followers in the best of their activities for the development of the organization and well-being of the human resources and believe that pedagogical development is the best construct for the organizational development. (table 6)

3. The $\mathrm{r}$ values $(.410, .415, .429, .427$ and .425$)$ which were significant at .000 showed significant positive correlation of authentic leadership attributes with pedagogical development (tables 7, 8. 9, 10 \&11)

4. The $r$ value (.436) which was significant at .000 showed significant positive and average level correlations between authentic leadership and pedagogical development at university level. (table 12)

5. The $\mathrm{r}$ value (.355) which was significant at .000 showed a significant positive and average level correlation in public sector universities between authentic leadership and pedagogical development at university level. (table 13)

6. The $r$ value (.529) which was significant at .000 showed a significant positive and average level correlation in private sector universities between authentic leadership and pedagogical development at university level. (table 13)

7. Most of the qualitative data support the quantitative data as all the major themes of the qualitative data such as self-awareness, relational transparency, ethical perspectives, positive psychological capital, and balance processing of information of authentic 
leadership supported the quantitative authentic leadership constructs taken from literature of empirical studies. Similarly, major themes emerged from qualitative data on pedagogical development supported the quantitative constructs taken from research studies.

\section{Discussions}

The present study adds to the authentic leadership literature by documenting empirical support of relations between authentic leadership attributes and pedagogical development. All hypothesized relations were supported by the data. As expected, authentic leadership attributes self-awareness (Walumbwa et al., 2008), relational transparency (Walumbwa et al., 2008; ClappSmith et al., 2009), ethical perspective (Walumbwa et al., 2008; Branson, 2010) and balance processing information were significantly positively related to pedagogical development (Winick, 2014; Koehler \& Mishra, 2009). This finding was consistent with Walumbwa et al. (2008), who found self-awareness, relational transparency, ethical perspective and balance processing of information as the constructs of authentic leadership.

It was found positive psychological capital attribute of authentic leadership to be significantly positively related to pedagogical development. This finding is in line with previous research of (Mishra \& Koehler, 2006).

Earlier empirical studies have related AL to both of attitudinal (Leroy, Palanski, \& Simons, 2012) and behavioral outcomes (Leroy, Anseel, Gardner, \& Sels, 2015). Empirical studies suggest that when leaders are aware of their moral standards and act upon such principles, they are more likely to gain higher levels of performance and assist others get done the same (Ryan \& Deci, 2001). Followers tend to express greater satisfaction with their leader when the leader involves in authentic actions and this satisfaction is likely to link to a growth in pedagogical development (Jensen \& Luthans, 2006). Harter (2005) presents a catalogue of psychological paybacks for being authentic, namely; higher self-esteem, more positive effect and more futuristic optimism. Mostly authentic leaders are more salient due to their inherent features and they influence their followers by their authentic deeds and positive relation and by this strong constructive relation with followers, authentic leaders surpass authenticity (Gardner, Avolio, Luthans, May \& Walumbwa, 2005). Liborius (2014) found that truth, meekness, mercy, concern, awareness and gratefulness towards followers positively correlated with followers' willingness to engage with their leader, and positively correlated with pedagogical development which favors the findings of this study. 
Authentic leadership is a process in which leaders and followers assist each other to make progress to a higher level of morale and motivation. It produces significant transformation in the life of individuals and organization, discernment and principles are reshaped, prospects and ambitions of followers are changed, leader's personality, is valued, role model is made for ethical development, vision is energized and goals are faced (Kotlyar \& Karakowsky, 2007).

Relational model is another strength which focus on the development of leaders and followers and that is not leader-centric, but giving followers their share of the power and responsibility in the leadership of a particular organization and the development of its members rather than just being resources to a production end (Dugan \& Komives, 2010).

\section{Recommendations}

In the light of findings and conclusions of the study following recommendations were made;

Authentic Leadership must be the theoretical lens through which all educational leadership development is perceived and developed. Since Begley (2006, p. 570) defines that Authentic Leadership "is a metaphor for professionally effective, ethically sound, and consciously reflective practices in educational administration", therefore, it is time for universities to encourage, motivate, progress and develop authentic leaders. Organizations in my country desires educational leaders who, while at the forward-facing line of defense is grooming and educating a new generation through authentic leadership as it is considered the architect of morality, are not guaranteed by position and prestige, but who lead by the attributes of authentic leadership. In reality, what this researcher actually learned from the study is that followers wish for Authentic Leadership in their universities.

Great shortage of research is found on Authentic Leadership and its relationships to any factor in the educational system of my country; therefore, the field is ready for ploughing. With Authentic Leadership as a theoretical framework for research, it is the informants' unanimous convictions that call for an innovative leadership approach with a purpose to restoring "confidence, hope, optimism, resiliency, and meaningfulness" in leadership practices (Avolio et al., 2004, p. 3) can and should start now. Since the results of this study support the idea that Authentic Leadership is a desirable leadership construct in this country, then further empirical research may be conducted in the field of education aiming at growing and developing authentic leaders, prepared them to meet the challenges of leading universities. Authentic leadership is still in the early stages of development, and much empirical research is looked-for to advocate the rich theoretical foundations of this theory. 
In terms of organizational development, Authentic Leadership, when demonstrated, has been shown to make available a firm underpinning for proper and viable organizational development (Luthans \& Avolio, 2003). Begley (2006) tackled the matter as it concerns to educational leaders, who he said must engage the university community regarding all relevant problems. This notion was further confirmed by the teachers in this study, who communicated their pleasure and yearning to work in an environment where Authentic Leadership is demonstrated. Since educational leadership is thought to present values (Branson, 2007) and an ethical attempt (Rintoul, 2010), and further, since Branson (2007) highlighted that leadership can be advanced through formal training, further research must face this requirement for training. And lastly, there has been a recent move in Authentic Leadership research toward the development of followers (Avolio \& Walumbwa, 2014). Additionally, study on follower development could shed light on how teachers might be trained in Authentic Leadership attributes in order to improve pedagogical development (Harvey, Martinko, \& Gardner, 2006).

It may be well to conduct research study on the authentic leadership at primary level, secondary level and college level both at private and public sectors as these areas are in great need of authentic leadership because these sectors suffered a lot due to unethical attitude of the leaders.

It becomes incumbent upon each and every researcher, leader and follower, who seeks the dignity and bliss of authentic leadership, to regulate his /her life according to the valuable constructs (attributes) of authentic leadership; as not accumulated wealth ( by hook or crook) but righteousness (authentic leadership attributes) attains the happy end; the gift of Nature and the solace of mind and soul come from adopting authentic leadership attributes; as authentic leadership creates purity, harmony, balance and transparency; and evil is doomed to perish. Authentic leadership is a guide and a mercy to men and teaches them wisdom- the path of Golden Mean-pure life.

\section{References}

Albert, J. F., \& Vadla, K. (2009). Authentic leadership development in the classroom: A narrative approach. Journal of Leadership Education, 8(1), 72-92.

Avolio, B. J., Gardner, W. L., Walumbwa, F. O., Luthans, F., \& May, D. R. (2004). Unlocking the mask: A look at the process by which authentic leader's impact follower attitudes and behaviors. The Leadership Quarterly, 15(3), 801-823. 
Avolio, B. J., \& Gardner, W. L. (2005). Authentic Leadership Development: Getting to the root of positive forms of leadership. The Leadership Quarterly(16), 315-338. Retrieved December 20, 2015

Ilies, R., Morgeson, F. P., \& Nahrgang, J. D. (2005). Authentic Leadership and the eudemoic well-being: understanding leader-follower outcomes. The Leadership Quarterly $16,343-394$

Jones, S. R., Kim, Y. C., \& Skendall, K. C. (2012). Re- Framing Authenticity: Considering Multiple Social Identities Using Auto ethnographic and Intersectional Approaches. The Journal of Higher Education, 83(5), 698-724.

Kernis, M. H. (2003). Toward a conceptualization of optimal self-esteem. Psychological Inquiry, 14, 1-26.

Leroy, H., Anseel, F., Gardner, W. L., \& Sels, L. (2015). Authentic leadership, authentic followership, basic need satisfaction, and work role performance: A cross-level study. Journal of Management, 41(6), 1677-1697.

Leroy, H., Palanski, M. E. \&Simons, T. (2012). Authentic leadership and behavioural integrity as drivers of follower commitment and performance. Journal of Business Ethics, 107(3), 255-264.

Liborius, P. (2014). Who is worthy of being followed? The impact of leaders' character and the moderating role of followers' personality. The Journal of psychology, 148(3), 347385.

Luthans, F., Youssef, C.M., Avolio, B.J. (2007). Psychological Capital: developing the human competitive edge. Oxford University Press, Oxford.

Northouse, P. G. (2013). Leadership: Theory and practice (6th Ed.). Thousand Oaks, CA: Sage.

Northouse, P. G. (2014). Introduction to leadership: Concepts and practice. Sage Publications.

Ryan, R. M., \& Deci, E. L. (2001). On happiness and human potentials: A review of research on hedonic and eudaimonic well-being. Annual review of psychology, 52(1), 141166.

Ryan, R. M. \& Deci, E. L. (2003). On assimilating identities to the self: A self-determination theory perspective on internalization and integrity within cultures. In M. R. Leary \& J. P. Tangney (Eds.), Handbook of self and identity (pp.253-270). New York: Guilford Press. Sage Publications.

Shamir, B. \& Eilam, G. (2005). What's your story? A Life-stories approach to Authentic Leadership Development. The Leadership Quarterly 16, 395-417.

Sparrowe, R. T. (2005). Authentic leadership and the narrative self. The Leadership Quarterly, 16, 419-439.

Walumbwa, F. O., Avolio, B. J., Gardner, W. L., Wernsing, T. S., \& Peterson, S. J. (2008). Authentic leadership: Development and validation of a theory-based measure. Journal of Management, 34(1), 89-126. 
Walumbwa, F. O., Wang, P., Wang, H., Schaubroeck, J., \& Avolio, B. J. (2010). Retracted: Psychological processes linking authentic leadership to follower behaviors. The Leadership Quarterly, 21(5), 901-914.

Walumbwa, F. O., Luthans, F., Avey, J. B., \& Oke, A. (2011). Retracted: Authentically leading groups: The mediating role of collective psychological capital and trust. Journal of Organizational Behavior, 32(1), 4-24.

Wang, H., Sui, Y., Luthans, F., Wang, D., \& Wu, Y. (2014). Impact of authentic leadership on performance: Role of followers' positive psychological capital and relational processes. Journal of Organizational Behavior, 35(1), 5-21.

Warszewska-Makuch, M., Bedyńska, S., \& Żołnierczyk-Zreda, D. (2015). Authentic leadership, social support and their role in workplace bullying and its mental health consequences. International Journal of Occupational Safety and Ergonomics, 21(2), $128-140$. 